\title{
The Efficacy And Safety Of Aspirin As The Primary Prevention Of Cardiovascular Disease: An Updated Meta-Analysis
}

This article was published in the following Dove Press journal:

Therapeutics and Clinical Risk Management

\author{
Wenchao Xie' \\ Ying Luo ${ }^{2}$ \\ Xiangwen Liang' \\ Zhihai Lin' \\ Zhengdong Wang' \\ Ming Liu' \\ 'Department of Cardiology, Sixth \\ Affiliated Hospital of Guangxi Medical \\ University, Yulin, Guangxi 537000, \\ People's Republic of China; ${ }^{2}$ Graduate \\ School, Guangxi Medical University, \\ Nanning, Guangxi 53002I, People's \\ Republic of China
}

Purpose: Information regarding the use of aspirin for patients with no known cardiovascular disease remains conflicting. We performed an updated meta-analysis to evaluate the efficacy and safety of aspirin for primary prevention of cardiovascular disease.

Patients and methods: PubMed, MEDLINE, and Cochrane library databases were searched for randomized controlled trials comparing aspirin with placebos or no treatment published up until November 1, 2018. The primary efficacy endpoint was all-cause death. The secondary endpoints included cardiovascular death, myocardial infarction, and stroke. The safety endpoints included major bleeding, gastrointestinal bleeding, and hemorrhagic stroke.

Results: Fourteen studies were included. Aspirin use was associated with a lower risk of myocardial infarction than placebo use or no treatment (risk ratio [RR], 0.83, 95\% confidence interval $[\mathrm{CI}]: 0.73-0.95, \mathrm{P}=0.005$ ). Additionally, compared with the control groups, aspirin use was not associated with a lower risk of all-cause mortality or cardiovascular mortality. In terms of safety, aspirin use was associated with a higher risk of major bleeding (RR, 1.40, 95\% CI: 1.25-1.57, P = 0.000), gastrointestinal bleeding (RR, $1.58,95 \% \mathrm{CI}$ : $1.25-1.99, \mathrm{P}=0.000)$, and hemorrhagic stroke ( $\mathrm{RR}, 1.30,95 \% \mathrm{CI}: 1.06-1.60, \mathrm{P}=0.011)$. Furthermore, the treatment effect was not significantly modified by patients' clinical characteristics. No publication bias was present.

Conclusion: Aspirin use reduced the myocardial infarction risk in patients without known cardiovascular disease, but had no effect in terms of reducing the risk of all-cause death, cardiovascular death, and stroke, and increased the risk of major bleeding, gastrointestinal bleeding, and hemorrhagic stroke.

Keywords: aspirin, primary prevention, cardiovascular disease, meta-analysis

\section{Introduction}

Cardiovascular disease is a leading cause of death worldwide, ${ }^{1}$ with approximately $24 \%$ of the global adult population dying from cardiovascular disease each year. ${ }^{2}$ Although evidence for aspirin as secondary prevention in patients with previous myocardial infarction or stroke is well defined, ${ }^{3}$ the use of aspirin in primary prevention of cardiovascular disease remains controversial. Certain studies have shown that aspirin can significantly decrease the rate of the main adverse cardiovascular events, ${ }^{4,5}$ whereas the results of other studies indicated contradictory findings. ${ }^{6,7}$

Moreover, recommendations regarding the daily use of low-dose aspirin also vary from guidelines to guidelines. ${ }^{8,9}$ For example, whereas the guidelines from the European Society of Cardiology do not recommend the use of aspirin as a primary
Department of Cardiology, Sixth Affiliated Hospital of Guangxi Medical University, 495 Education Road, Yulin, Guangxi 537000, People's Republic of China $\mathrm{Tel} / \mathrm{Fax}+8607752683223$

Email yulinlm@yeah.net 
prevention for cardiovascular disease in any population because of the risk of increasing major bleeding, ${ }^{9}$ the 2016 United States Preventive Services Task Force (USPSTF) statement recommended low-dose aspirin use for the primary prevention of CVD in adults aged 50 to 59 years who have a $10 \%$ or greater 10 -year CVD risk without increased risk for bleeding. ${ }^{8}$ Therefore, whether aspirin can be used for primary prevention of cardiovascular disease remains inconclusive.

Recently, a number of related studies (e.g., ASPREE, ARRIVE and ASCEND trials) have published results. ${ }^{10-12}$ Therefore, we performed an updated meta-analysis by including the latest evidence to evaluate the efficacy and safety of aspirin for primary prevention of cardiovascular disease.

\section{Materials And Methods}

This study was conducted in accordance with the Preferred Reporting Items for Systematic Reviews and Meta-Analyses (PRISMA) guidelines to evaluate the efficacy and safety of aspirin for primary prevention of cardiovascular disease. ${ }^{13}$

\section{Search Strategy}

We searched PubMed, MEDLINE, and the Cochrane library databases using the keywords "aspirin," "cardiovascular disease," and "primary prevention." We also searched clinicaltrials.gov for more detail regarding the clinical trials. The language of all studies was in English. The time limit for publication of the literature was up until November 1, 2018.

\section{Inclusion And Exclusion Criteria}

The inclusion criteria were as follows: 1) the subjects in the study were adult patients ( $\geq 18$ years) without a history of cardiovascular disease; 2) subjects in the study were using aspirin; 3) the control treatment used was a placebo or no treatment; 4) the study should report our outcomes of interest, namely all-cause death, cardiovascular death, myocardial infarction, stroke, major bleeding, and gastrointestinal bleeding; and 5) the type of study was a randomized controlled trial. If the same research has been reported in multiple publications, we included the most recently published research.

The exclusion criteria were as follows: 1) the study included subjects with known history of cardiovascular disease; 2) aspirin was not used; 3) the study was without a control group; 4) the study did not report our designated outcomes; and 5) the study was an observational study, conference report, or corresponding letter.

\section{The Outcomes Of The Study}

The primary efficacy endpoint was all-cause death. The secondary efficacy endpoints included cardiovascular death, myocardial infarction, and stroke. The primary safety endpoints were major bleeding. The secondary safety endpoints included gastrointestinal bleeding and hemorrhagic stroke. All the outcomes were defined according to the definition used in each trial.

\section{Data Extraction And Quality Evaluation}

Two researchers read the full texts of each evaluated literature source and extracted the relevant information, which included the year of study, the country of research, the percentage of male patients, mean age of patients, the percentage of patients with diabetes mellitus, the dose of aspirin, and the follow-up time. If two the researchers disputed any point in the process of extracting information, a third researcher would pass judgment and make a final decision. We used the Cochrane risk-of-bias tool to evaluate the quality of all included randomized controlled trials. $^{14}$

\section{Statistical Analysis}

We used the risk ratios (RRs) and the corresponding 95\% confidence interval (CI) as the effect measure of dichotomous data. We performed $\mathrm{I}^{2}$ and Cochran $\mathrm{Q}$ tests to evaluate the heterogeneity between studies. An $\mathrm{I}^{2}$ value $<$ $25 \%$ indicated that there was low heterogeneity between the studies; $25 \%<\mathrm{I}^{2}<50 \%$ indicated that there was moderate heterogeneity between the studies; and $\mathrm{I}^{2} \geq$ $50 \%$ indicated that there was a high degree of heterogeneity between the studies. ${ }^{15}$ To account for unexplained heterogeneity, we performed the meta-analysis using a random-effects model (DerSimonian-Laird method). ${ }^{16}$ We used Begg's funnel plots and Egger's regression symmetry tests to detect publication bias. ${ }^{17}$ Subgroup analyses were performed based on population characteristics, such as the mean age of the population, the dosage of aspirin, the percentage of patients with diabetes mellitus, the percentage of male patients, and BMI. Meta-analysis was performed using STATA12.0 software.

\section{Results}

A flow diagram of the literature search and study selection process is shown in Figure 1. We found 1686 studies from a search of PubMed, MEDLINE, the Cochrane library databases, and the reference lists of relevant papers. 


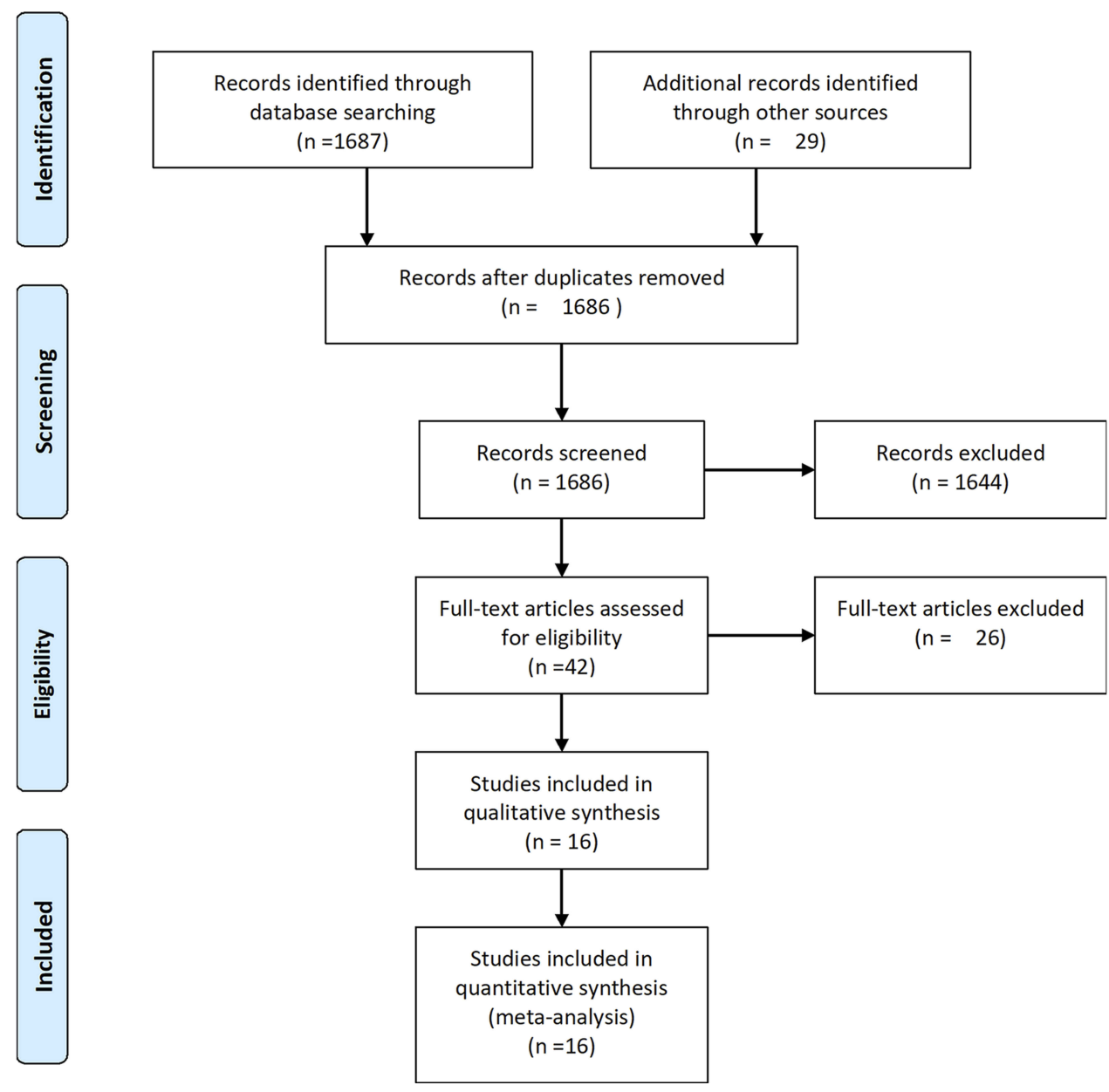

Figure I The PRISMA flow diagram.

Finally, 16 studies involving 139,392 patients met the inclusion criteria. ${ }^{4-7,10-12,18-26}$ Three studies were different reports of one trial; therefore a total of 14 studies were included. ${ }^{11,18,19}$ The characteristics of the studies included in the analysis and their populations are listed in Table 1. The mean age of patients ranged from 55 to 74 years. Three trials included only male patients and one trial included only female patients. Most of the selected studies did not report the mean weight of patients, and included patients with a BMI higher than $24 \mathrm{~kg} / \mathrm{m}^{2}$. Most patients were taking the low-dose aspirin (81 or $100 \mathrm{mg}$ per day) while three studies reported patients taking the high-dose aspirin. $^{24-26}$ Three trials included patients with diabetes mellitus. The follow-up time ranged from 4 to 10 years. An assessment of the risk of bias of the included studies is presented in Figure 2. Overall, the included studies were found to have a low risk of bias.

\section{The Clinical Outcome Of Studies} All-Cause Mortality

Fifteen studies ${ }^{4-7,11,12,18-26}$ were included and the results showed that the use of aspirin was not associated with a lower risk of all-cause mortality compared with the control group (RR, 0.97, 95\% CI: 0.93-1.02, P $=0.266 ; \mathrm{I}^{2}=0 \%, \mathrm{P}$ $=0.589$ ) (shown in Figure 3).

\section{Cardiovascular Mortality}

Fifteen studies ${ }^{4-7,11,12,18-26}$ were included and the results showed that the use of aspirin was not associated with a lower risk of cardiovascular mortality compared with the control group (RR, 0.93, 95\% CI: 0.85-1.01, P = 0.096; $\mathrm{I}^{2}=0 \%, \mathrm{P}=0.452$ ). (shown in Figure 4).

\section{Myocardial Infarction}

Fifteen studies ${ }^{4-7,11,12,18-21,23-26}$ were included and the results showed that the use of aspirin was associated with a 


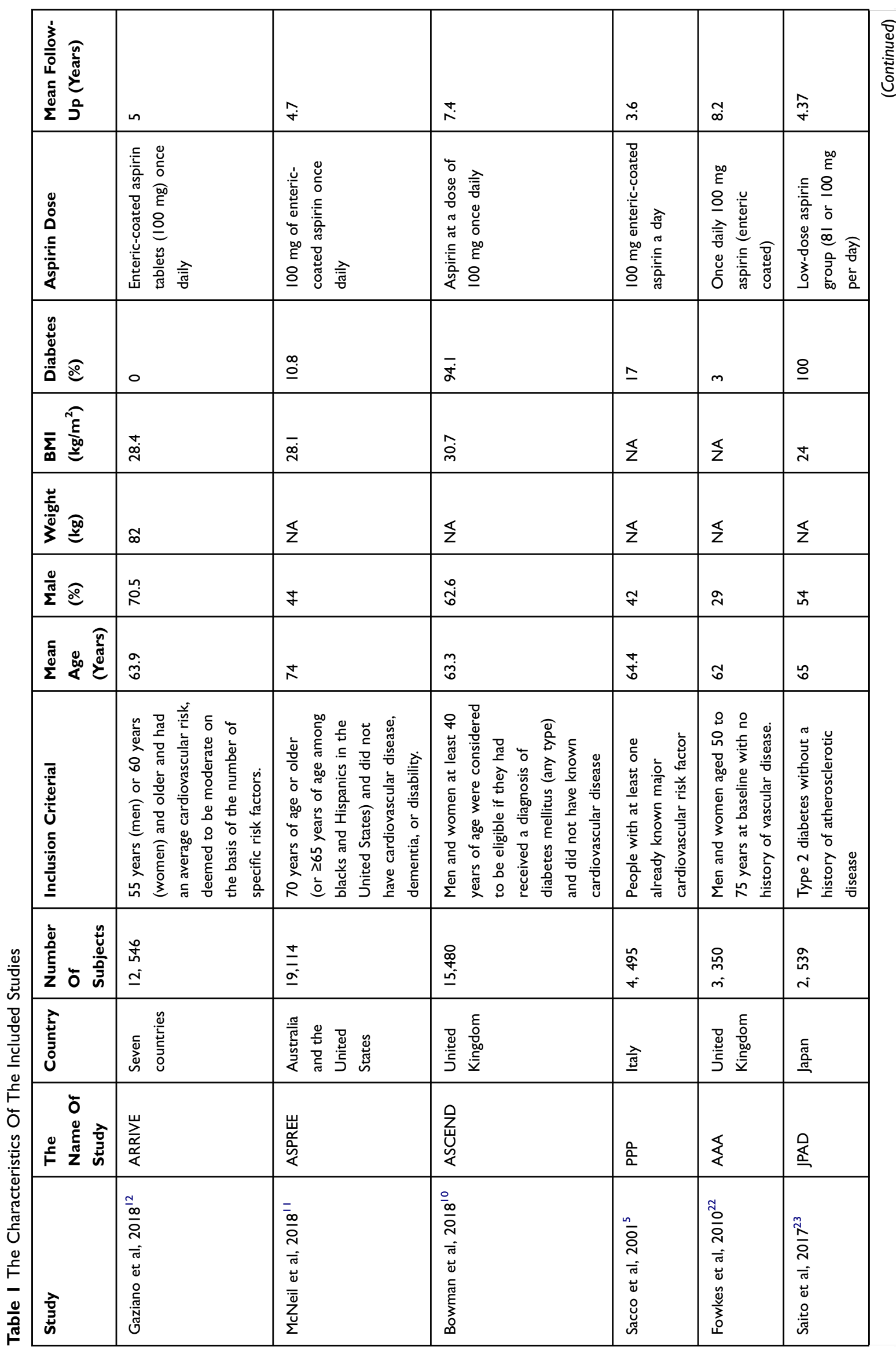




\begin{tabular}{|c|c|c|c|c|c|c|c|c|}
\hline 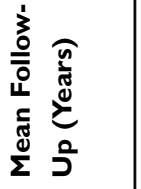 & $\stackrel{\text { นn }}{0}$ & $\hat{\jmath}$ & $\overline{\underline{O}}$ & in & in & $\underset{\omega}{\infty}$ & 0 & $\stackrel{\infty}{m}$ \\
\hline 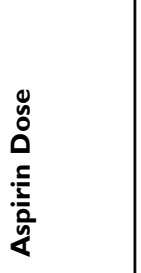 & 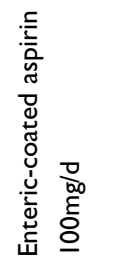 & 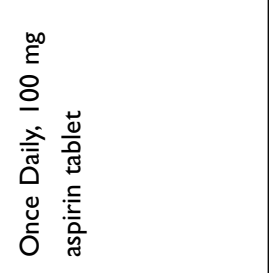 & 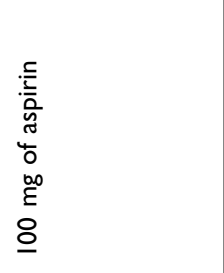 & 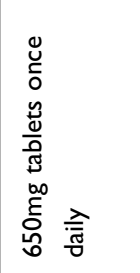 & 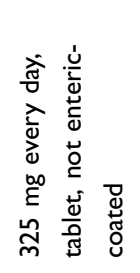 & 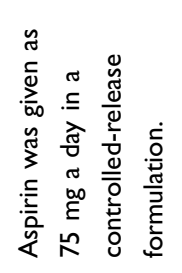 & 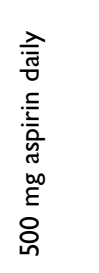 & 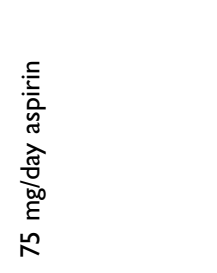 \\
\hline 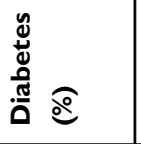 & $\stackrel{a}{\tilde{m}}$ & 으 & $\stackrel{\circ}{i}$ & 으 & $\S$ & $\S$ & $\stackrel{\circ}{\mathrm{i}}$ & $\infty_{\infty}^{\circ}$ \\
\hline 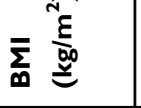 & $\stackrel{\sim}{\sim}$ & సి & $\stackrel{\sim}{\sim}$ & $\S$ & $\S$ & $\stackrel{+}{\stackrel{\sim}{~}}$ & $\mathbb{z}$ & $\begin{array}{l}\stackrel{\sim}{\infty} \\
\underset{\sim}{\infty}\end{array}$ \\
\hline 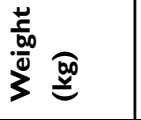 & $\stackrel{\leftrightarrow}{\infty}$ & $\S$ & $\S$ & $\mathbb{z}$ & $\S$ & $\mathbb{Z}$ & $\S$ & $\S$ \\
\hline$\frac{\frac{0}{\pi}}{\Sigma} \circlearrowright$ & 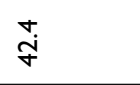 & $\mathcal{F}$ & 0 & น゚ & 으 & 으 & 으 & $\tilde{n}$ \\
\hline 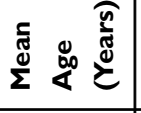 & 迎 & $\overline{8}$ & 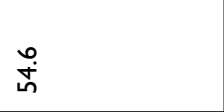 & $\S$ & $\S$ & $\stackrel{n ?}{\text { in }}$ & $\mathbb{Z}$ & $\frac{n}{\frac{n}{0}}$ \\
\hline 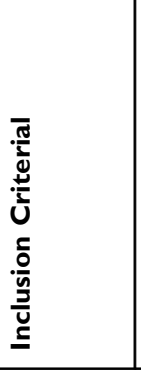 & 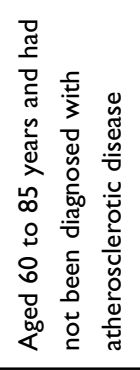 & 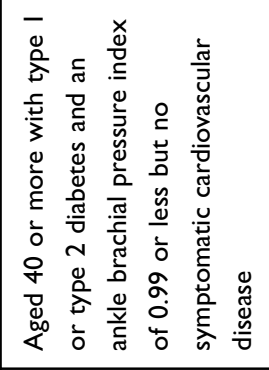 & 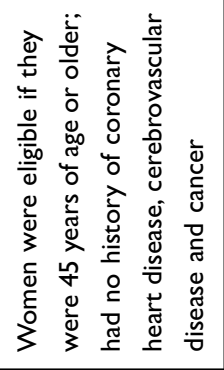 & 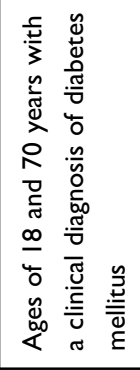 & 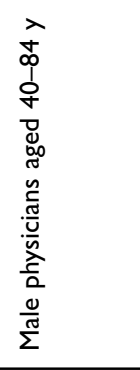 & 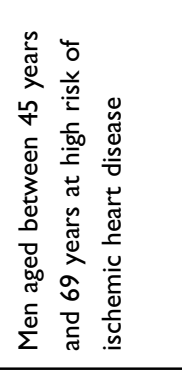 & 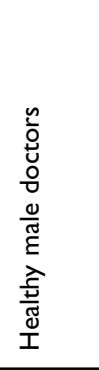 & 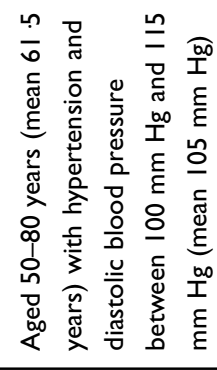 \\
\hline 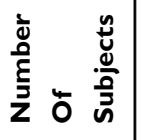 & $\begin{array}{l}\infty_{0}^{\infty} \\
\dot{ \pm}\end{array}$ & 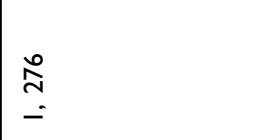 & $\begin{array}{l}\stackrel{0}{\infty} \\
\text { o. } \\
\text { m. }\end{array}$ & $\begin{array}{l}\bar{N} \\
\dot{m}\end{array}$ & $\begin{array}{l}\overline{0} \\
\text { ה }\end{array}$ & $\begin{array}{l}\text { or } \\
\text { ch } \\
i\end{array}$ & $\frac{\hat{m}}{\dot{m}}$ & $\begin{array}{l}\stackrel{2}{\curvearrowright} \\
\infty\end{array}$ \\
\hline نे & 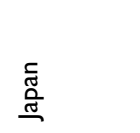 & 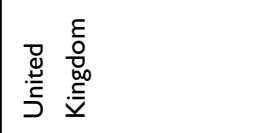 & 总 & 总 & 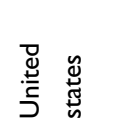 & 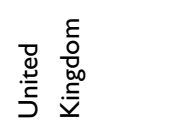 & 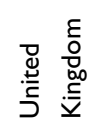 & ๙ \\
\hline 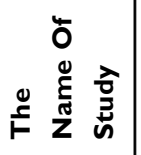 & $\begin{array}{l}\frac{a}{\underline{a}} \\
\underline{\underline{a}}\end{array}$ & 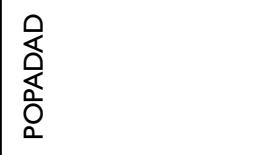 & $\stackrel{0}{3}$ & $\begin{array}{l}\mathscr{n} \\
\stackrel{0}{0} \\
\text { w }\end{array}$ & $\overline{\bar{T}}$ & $\stackrel{b}{r}$ & $\sum_{\infty}^{\infty}$ & 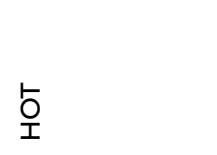 \\
\hline خे & 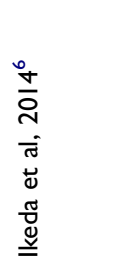 & 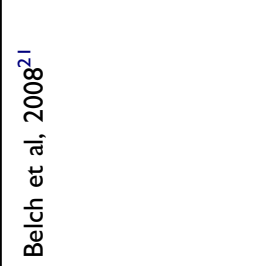 & 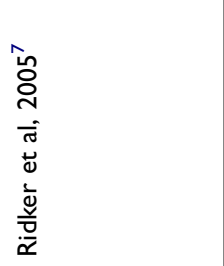 & 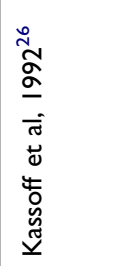 & 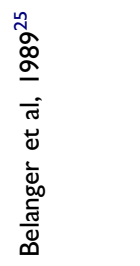 & 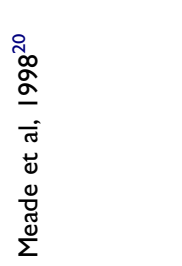 & 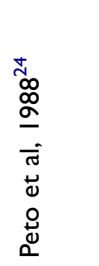 & 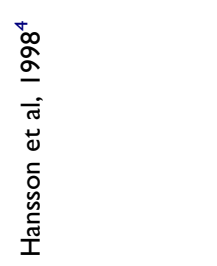 \\
\hline
\end{tabular}




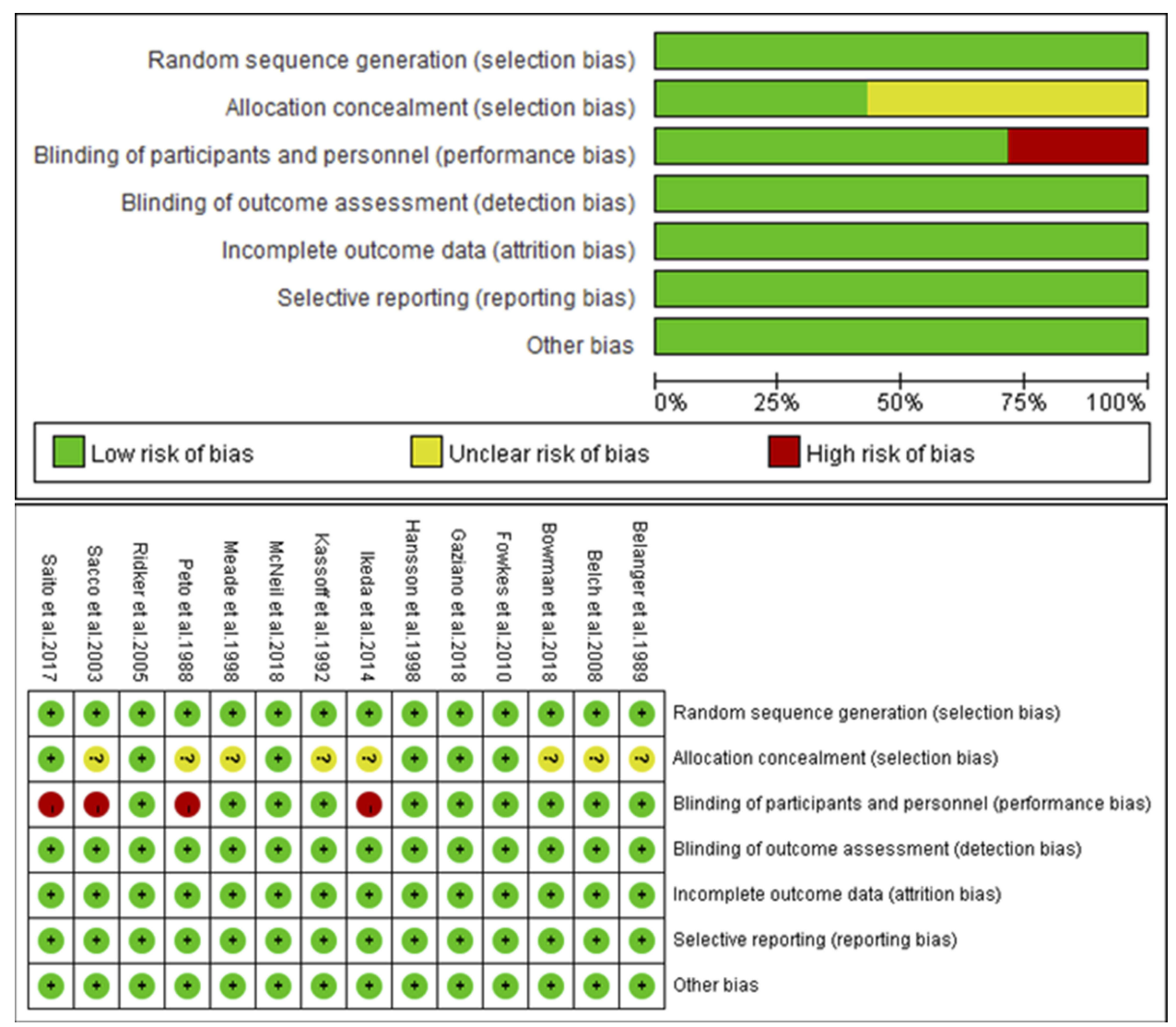

Figure 2 Assessment of the risk of bias of the included studies.

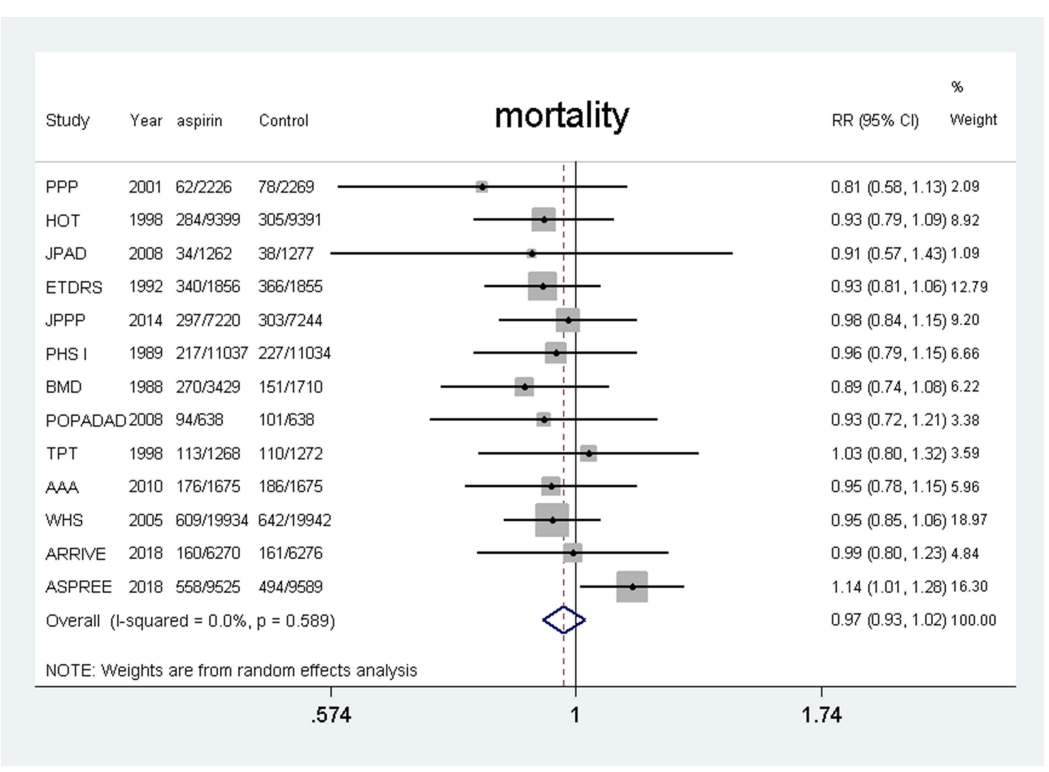

Figure 3 Benefit of aspirin for all-cause mortality.

lower risk of myocardial infarction compared with the Stroke

control group (RR, 0.83, 95\% CI: $0.73-0.95, \mathrm{P}=0.005$; Fifteen studies ${ }^{5-7,11,12,18-26}$ were included and the results $\mathrm{I}^{2}=57.8 \%, \mathrm{P}=0.005$ ). (shown in Figure 5). showed that the use of aspirin was not associated with a 


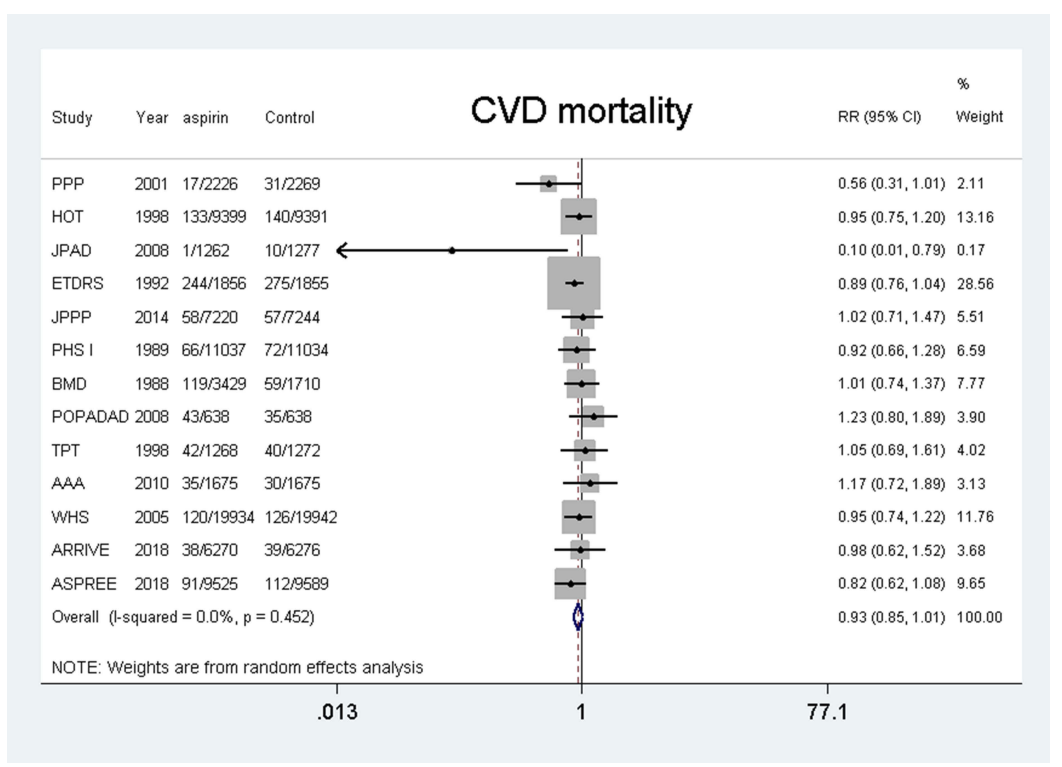

Figure 4 Benefit of aspirin for cardiovascular mortality.

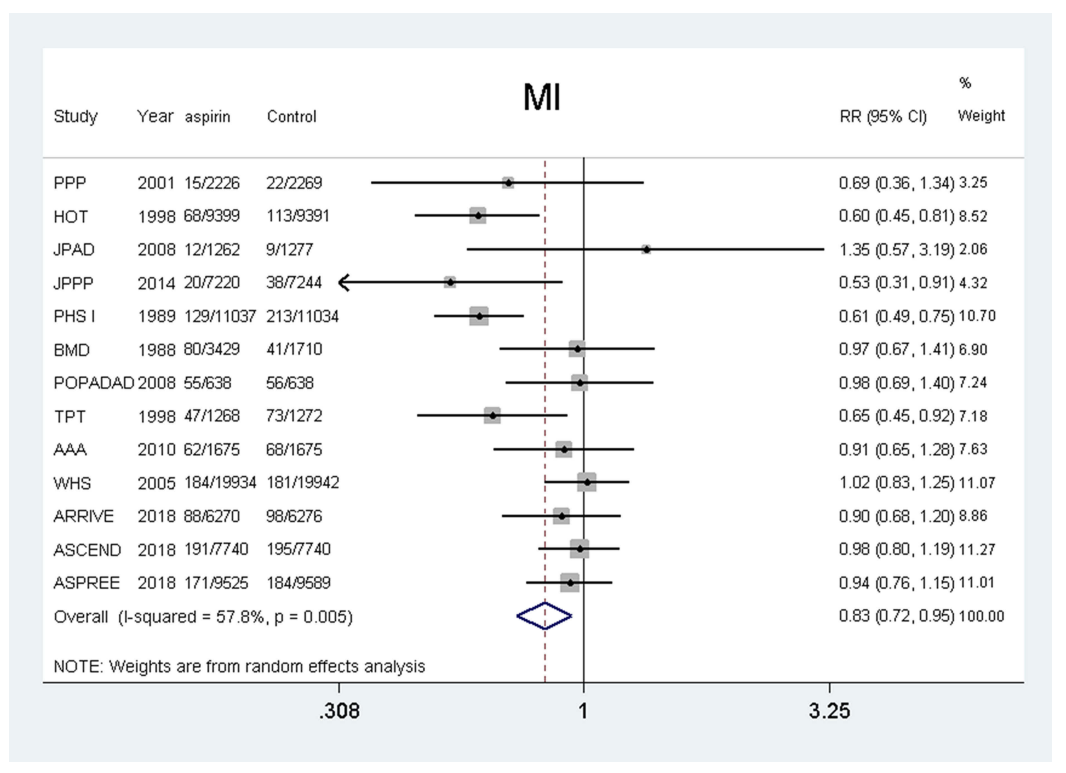

Figure 5 Benefit of aspirin for myocardial infarction.

lower risk of stroke compared with the control group (RR, $0.95,95 \%$ CI: $0.86-1.03, \mathrm{P}=0.208 ; \mathrm{I}^{2}=8.2 \%, \mathrm{P}=0.364$ ). (shown in Figure 6).

\section{Major Bleeding}

Five studies, ${ }^{40,11,20,22}$ were included and the results showed that the using of aspirin was associated with a higher risk of major bleeding compared with the control group (RR, 1.40, 95\% CI: $1.25-1.57, \mathrm{P}=0.000 ; \mathrm{I}^{2}=9.1 \%$, $\mathrm{P}=0.355$ ). (shown in Figure 7).

\section{Gastrointestinal Bleeding}

Fourteen trials ${ }^{4-7,10-12,18-24}$ were included and the results showed that the use of aspirin was associated with a higher risk of gastrointestinal bleeding compared with the control group (RR, 1.58, 95\% CI: $1.25-1.99, \mathrm{P}=0.000 ; \mathrm{I}^{2}=79.6 \%$, $\mathrm{P}=0.000$ ). (shown in Figure 8).

\section{Hemorrhagic Stroke}

Eleven studies ${ }^{6,7,10-12,18-20,22,23,25}$ were included and the results showed that the use of aspirin was associated with a 


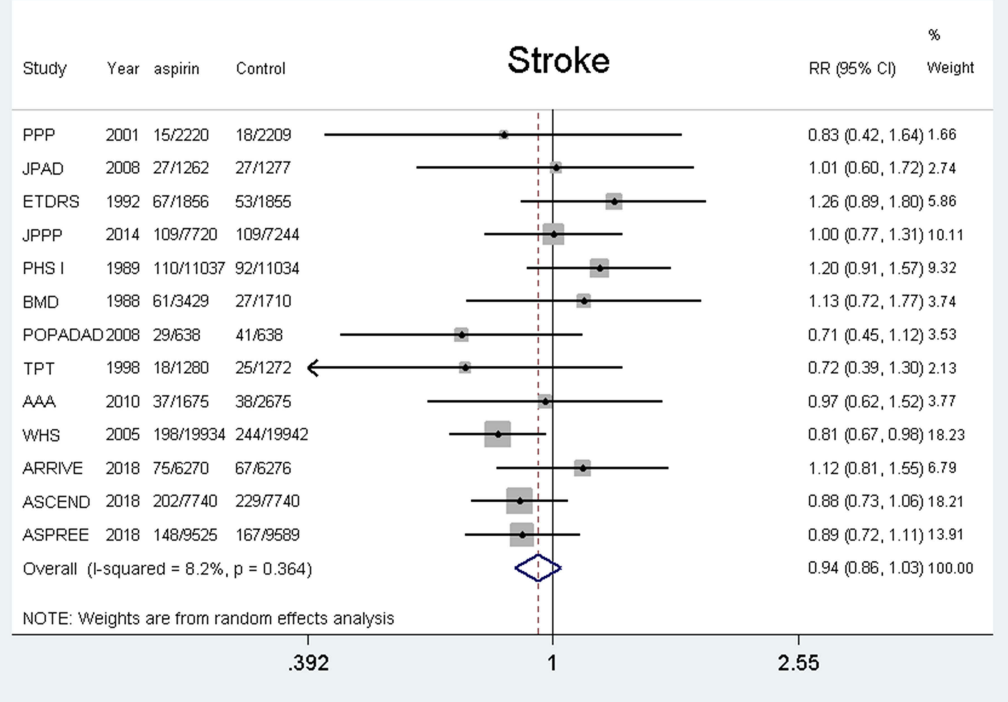

Figure 6 Benefit of aspirin for stroke.

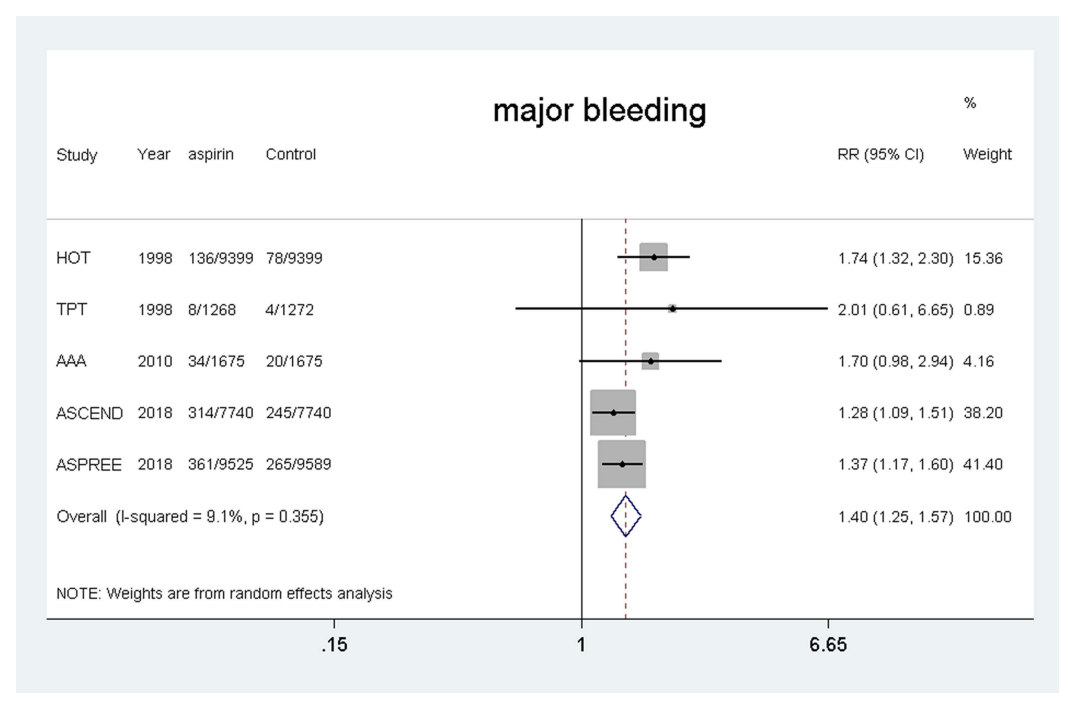

Figure 7 Safety of aspirin for major bleeding.

higher risk of hemorrhagic stroke compared with the control group (RR, 1.30, 95\% CI: 1.06-1.60, $\mathrm{P}=0.011 ; \mathrm{I}^{2}=$ $0 \%, \mathrm{P}=0.529$ ). (shown in Figure 9).

\section{Additional Analysis}

Results of the subgroup analysis are displayed in Table 2. The results showed no evidence that the treatment effect of all-cause mortality was significantly modified by patients' clinical characteristics. The comparison-adjusted funnel plots are shown in Figure 10. The results indicated that no publication bias was present.

\section{Discussion}

This updated meta-analysis, including three of the latest trials, showed that the use of aspirin was associated with a lower risk of myocardial infarction in patients without known cardiovascular disease. However, aspirin usage had no effect in terms of reducing the risk of all-cause 


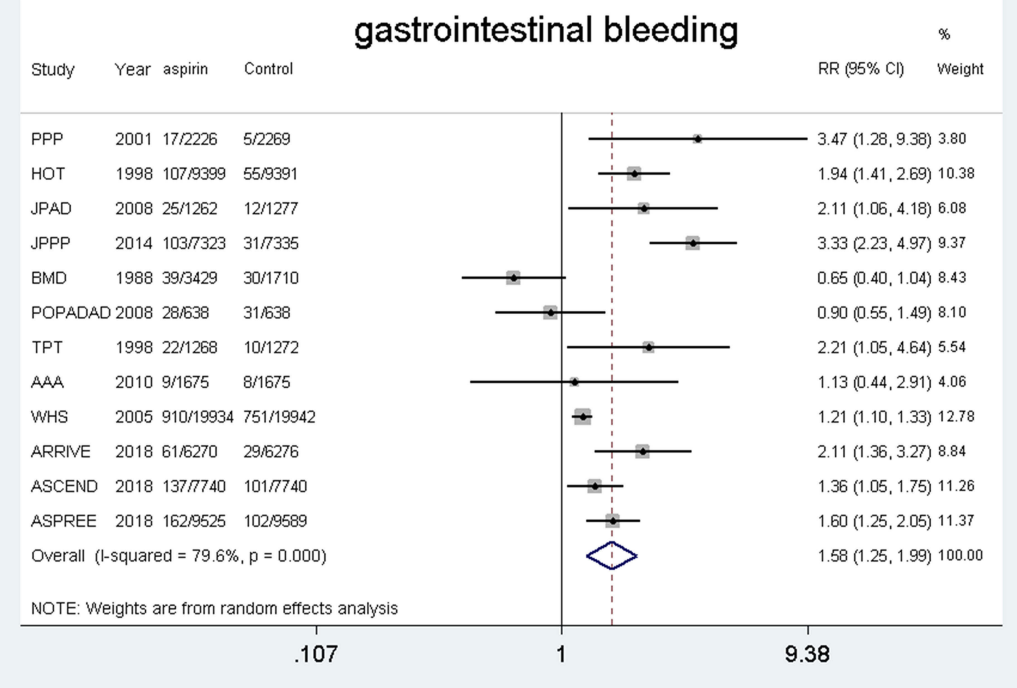

Figure 8 Safety of aspirin for gastrointestinal bleeding.

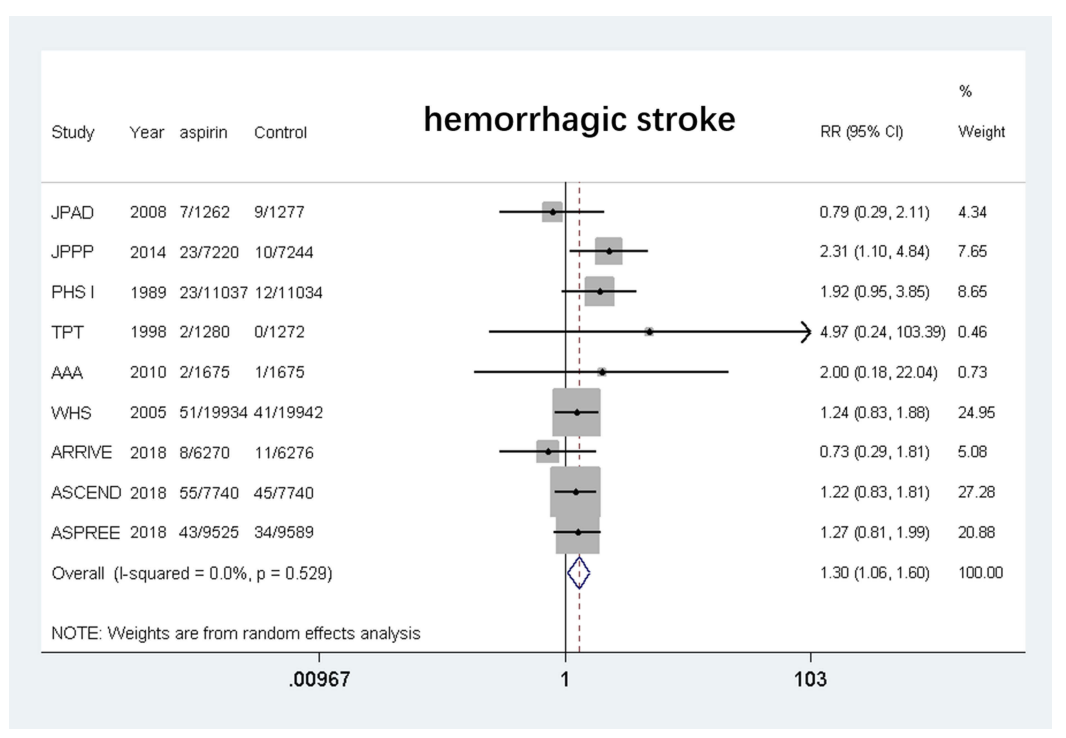

Figure 9 Safety of aspirin for hemorrhagic stroke.

death, cardiovascular death, or stroke, and increased the risk of major bleeding, gastrointestinal bleeding, and hemorrhagic stroke.

\section{Comparison With Other Studies}

Aspirin is commonly used for primary prevention in patients with a high risk of cardiovascular disease. However, issues regarding the use of aspirin for the primary prevention of cardiovascular disease in low- or intermediate-risk populations are still inconclusive. In 2009, the Antithrombotic Trialists Collaboration (ATTC) pooled six large-scale clinical trials that included a total of 95,456 patients with a 10 -year risk of cardiovascular disease at low risk, with an average follow-up of 6.9 years. ${ }^{27}$ The results showed that aspirin reduced the rate of major cardiovascular events (including myocardial infarction, stroke, and cardiovascular death) by $12 \%$ and reduced the event rate of non-fatal myocardial infarction by $23 \%$. However, aspirin was not associated with a lower risk of allcause mortality, cardiovascular death, or stroke, and the incidence of major bleeding in extracranial (mainly digestive tract) regions increased by $54 \%$. Moreover, the results of other meta-analyses that have evaluated the efficacy and safety of aspirin for primary prevention indicate that the use of aspirin does not reduce the risk of all-cause mortality. ${ }^{28-30}$ 
Table 2 The Results Of Subgroup Analysis

\begin{tabular}{|l|l|}
\hline The Variable & $\begin{array}{l}\text { Estimated Relative Treatment } \\
\text { Effects RR(95\% Cl) }\end{array}$ \\
\hline $\begin{array}{l}\text { Age } \\
<65 \text { years } \\
\geq 65 \text { years }\end{array}$ & $\begin{array}{l}0.95(0.88-1.02) \\
1.06(0.97-1.15)\end{array}$ \\
\hline $\begin{array}{l}\text { Gender } \\
\text { The percentage of male } \\
\text { was } 100 \% \\
\text { Others }\end{array}$ & $1.06(0.97-1.15)$ \\
\hline $\begin{array}{l}\text { The dosage of aspirin } \\
\leq 100 \mathrm{mg} / \mathrm{d} \\
>100 \mathrm{mg} / \mathrm{d}\end{array}$ & $0.98(0.93-1.03)$ \\
\hline $\begin{array}{l}\text { BMI } \\
<28 \mathrm{~kg} / \mathrm{m}^{2}\end{array}$ & $0.99(0.94-1.05)$ \\
$\geq 28 \mathrm{~kg} / \mathrm{m}^{2}$ & $0.93(0.84-1.02)$ \\
\hline $\begin{array}{l}\text { DM } \\
\text { The percentage of DM } \\
\text { was } 100 \% \\
\text { Others }\end{array}$ & $0.98(0.93-1.03)$ \\
\hline
\end{tabular}

Recently, three clinical studies have further evaluated the efficacy and safety of aspirin for the primary prevention of cardiovascular disease. ${ }^{10-12}$ The results of the ARRIVE study, which included 12,546 patients with a low risk of cardiovascular risk and no history of diabetes, with a median follow-up time of 60 months, ${ }^{12}$ indicated that oral aspirin had no effect in terms of reducing the main cardiovascular events (including cardiovascular death, myocardial infarction, instability angina, stroke, and transient ischemic attack (TIA)), but significantly increased the risk of gastrointestinal bleeding. The results of the ASPREE study, which included 19,114 elderly patients with an average age of 70 years without cardiovascular disease and a follow-up time was 4.7 years, ${ }^{11}$ indicated that the use of aspirin did not prolong the disease-free survival of these patients, but significantly increased the risk of major bleeding. The results of the ASCEND study, which included 15,480 patients with diabetes but without known cardiovascular disease, ${ }^{10}$ indicated that the use of aspirin reduced the incidence of severe vascular events (including myocardial infarction, stroke, TIA, or angiogenic death) by $22 \%$, but increased the risk of major bleeding by $29 \%$. The findings of the present analyses tend to be consistent with the findings of these studies, and indicate that although taking aspirin reduces the risk of myocardial infarction in patients with no previous cardiovascular disease, it has no effect with regards to reducing the rates of all-cause death, cardiovascular death, and stroke. Moreover, the use of aspirin is also associated with increases in the risk of major bleeding, gastrointestinal bleeding, and hemorrhage stroke. Our subgroup analysis also showed that the treatment effect was not significantly modified by patients' clinical characteristics. A previous study demonstrated that the reduced risk of major adverse cardiovascular events upon aspirin administration was initially offset by an increased risk of major bleeding, but effects on both outcomes diminished with increasing follow-up. ${ }^{31}$

In our study, the included patients were with a low risk of cardiovascular disease, and the event rate of cardiovascular mortality was very low. Additionally, in regards of
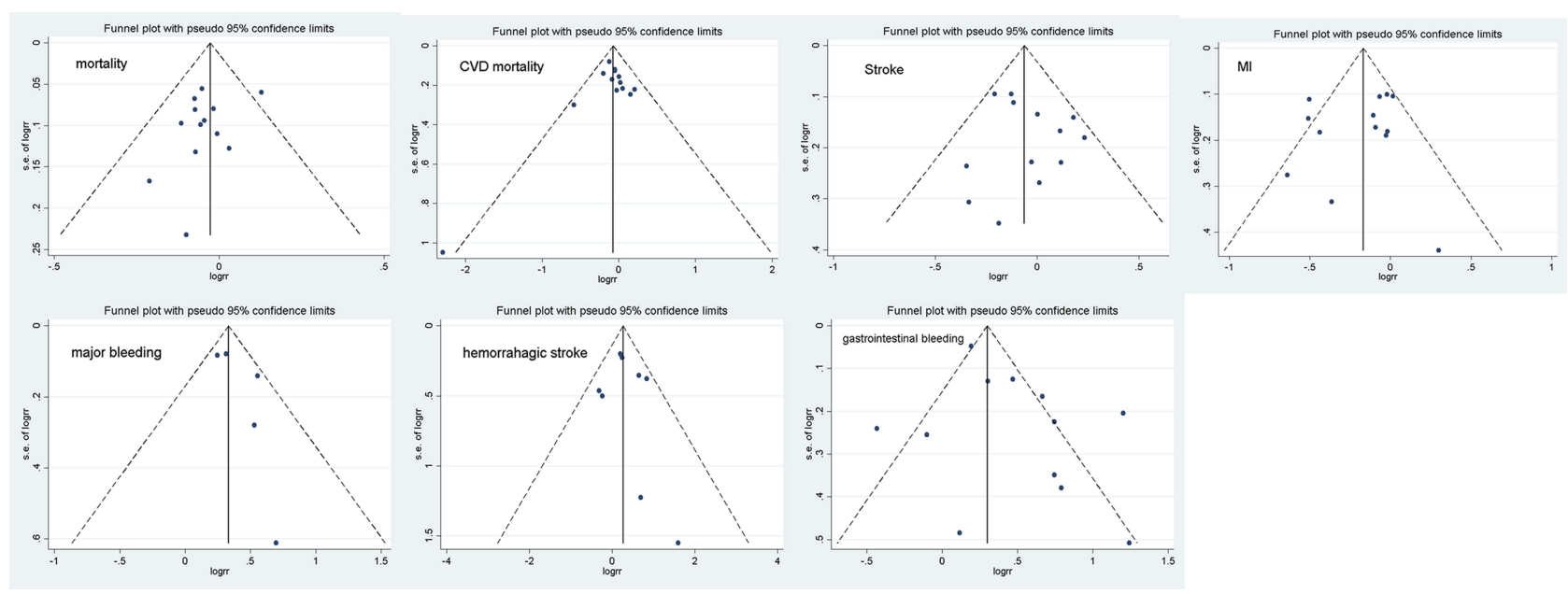

Figure 10 The funnel plot in the meta-analysis. 
the duration of the observation employed in the different trials, the time-frame adopted may not be sufficient to conclude the prevention of cardiovascular mortality. The outcome of stroke in our study accounted for the ischemic and hemorrhagic stroke. Aspirin was associated with increased risk of hemorrhagic stroke, which offset the benefit in reduction of ischemic stroke.

\section{The Clinical Implication Of The Study}

Among the patients evaluated in this study, aspirin was used as a primary prevention in adults without a history of coronary heart disease or stroke, which made it difficult to examine the benefit and harm associated with aspirin usage. Additionally, the currently used tool for assessment of benefits and risk are inaccurate. Studies have shown that increased age, race, sex, diabetes, current smoking status, and high blood pressure, which are normally associated with cardiovascular events, are also risk factors for bleeding. Therefore, the greater the benefit of aspirin therapy, the greater the risk of bleeding. ${ }^{27}$ Patients can obtain a clinical net benefit when the benefit of preventing a cardiovascular event significantly exceeds the risk of bleeding. The results of this study indicate that aspirin does not reduce the rate of all-cause death or cardiovascular death in patients with low and intermediate risk but does increase the risk of major bleeding. Further analysis showed that the treatment effect was not significantly modified by patients' clinical characteristics. Therefore, the use of aspirin may not confer any benefits to patients with a low or intermediate risk of cardiovascular disease.

\section{The Strengths And Limitations Of The Study}

This study has several strengths. First, to the best of our knowledge, this study is the largest meta-analysis to date that incorporates the latest clinical data. Secondly, we set multiple efficacy and safety endpoints to provide a more comprehensive review of the efficacy and safety of aspirin. Finally, we also conducted a subgroup analysis based on characteristics of the populations, such as the mean age, BMI, and the percentage of patients with diabetes, to identify the particular population for whom aspirin usage would be more suitable for the primary prevention of cardiovascular disease.

This study, however, has limitations. Some of the studies evaluated were published over 10 years ago, which can make them outdated. Second, the smoking rates of patients included in these studies tended to be high, and the use of drugs that improve prognosis such as statins was low. Therefore, differences among publication dates may lead to a heterogeneity among studies. Third, some information regarding population characteristics, such as average age and weight, was not fully extracted; therefore, these population characteristics were not included in the subgroup analyses. Fourth, the issue of aspirin compliance was not addressed in the present study because most of the information relating to aspirin compliance was unavailable. Fifth, the definition of endpoints between the included studies is inconsistent, which may have resulted in inaccurate reporting. Sixth, the patients in the included studies were with a low or intermediate risk of cardiovascular disease; for instance, in the ASCEND study, 2.5\% of patients were with myocardial infarction during a mean follow-up of 7.4 years. Therefore, we could not compare the results of our study with results reported on other patients with a high risk of cardiovascular disease.

\section{Conclusion}

The use of aspirin was found to reduce the risk of myocardial infarction in patients without known cardiovascular disease but had no effect in reducing the risk of all-cause death, cardiovascular death, and stroke, and increased the risk of major bleeding, gastrointestinal bleeding, and hemorrhagic stroke.

\section{Disclosure}

Wenchao Xie and Ying Luo are the first co-authors. The authors report no conflicts of interest in this work.

\section{References}

1. Lopez AD, Mathers CD, Ezzati M, Jamison DT, Murray CJ. Global and regional burden of disease and risk factors, 2001: systematic analysis of population health data. Lancet. 2006;367(9524):17471757. doi:10.1016/S0140-6736(06)68770-9

2. World Health Organization. The top 10 causes of death. 2011. Available from: http://www.who.int/mediacentre/factsheets/fs310/en/ index.html. Accessed November 27.

3. Antithrombotic Trialists C. Collaborative meta-analysis of randomised trials of antiplatelet therapy for prevention of death, myocardial infarction, and stroke in high risk patients. BMJ. 2002;324(7329):71-86. doi:10.1136/bmj.324.7329.71

4. Hansson L, Zanchetti A, Carruthers SG, et al.; HOT Study Group, Effects of intensive blood-pressure lowering and low-dose aspirin in patients with hypertension: principal results of the Hypertension Optimal Treatment (HOT) randomised trial. Lancet. 1998;351 (9118):1755-1762. doi:10.1016/s0140-6736(98)04311-6.

5. de Gaetano G; Collaborative Group of the Primary Prevention P. Lowdose aspirin and vitamin $\mathrm{E}$ in people at cardiovascular risk: a randomised trial in general practice. Collaborative Group of the Primary Prevention Project. Lancet. 2001;357(9250):89-95. doi:10.1016/ s0140-6736(00)03539-x 
6. Ikeda Y, Shimada K, Teramoto T, et al. Low-dose aspirin for primary prevention of cardiovascular events in Japanese patients 60 years or older with atherosclerotic risk factors: a randomized clinical trial. JAMA. 2014;312(23):2510-2520. doi:10.1001/jama.2014.15690

7. Ridker PM, Cook NR, Lee IM, et al. A randomized trial of low-dose aspirin in the primary prevention of cardiovascular disease in women. $N$ Engl J Med. 2005;352(13):1293-1304. doi:10.1056/NEJMoa050613

8. Bibbins-Domingo K; Force USPST. Aspirin use for the primary prevention of cardiovascular disease and colorectal cancer: U.S. Preventive Services Task Force recommendation statement. Ann Intern Med. 2016;164(12):836-845. doi:10.7326/M16-0577

9. Piepoli MF, Hoes AW, Agewall S, et al. European Guidelines on cardiovascular disease prevention in clinical practice: the Sixth Joint Task Force of the European Society of Cardiology and Other Societies on Cardiovascular Disease Prevention in Clinical Practice (constituted by representatives of 10 societies and by invited experts) Developed with the special contribution of the European Association for Cardiovascular Prevention \& Rehabilitation (EACPR). Eur Heart J. 2016;37(29):2315-2381. doi:10.1093/eurheartj/ehw106

10. Bowman L, Mafham M, Wallendszus K, et al.; Group ASC. Effects of aspirin for primary prevention in persons with diabetes mellitus. $N$ Engl J Med. 2018;379(16):1529-1539. doi:10.1056/NEJMoa1804988

11. McNeil JJ, Wolfe R, Woods RL, et al. Effect of aspirin on cardiovascular events and bleeding in the healthy elderly. $N$ Engl J Med. 2018;379(16):1509-1518. doi:10.1056/NEJMoa1805819

12. Gaziano JM, Brotons C, Coppolecchia R, et al. Use of aspirin to reduce risk of initial vascular events in patients at moderate risk of cardiovascular disease (ARRIVE): a randomised, double-blind, placebo-controlled trial. Lancet. 2018;392(10152):1036-1046. doi:10.1016/S0140-6736(18)31924-X

13. Moher D, Liberati A, Tetzlaff J, Altman DG; Group P. Preferred reporting items for systematic reviews and meta-analyses: the PRISMA statement. PLoS Med. 2009;6(7):e1000097. doi:10.1371/ journal.pmed.1000097

14. Higgins JP, Altman DG, Gotzsche PC, et al. The Cochrane Collaboration's tool for assessing risk of bias in randomised trials. BMJ. 2011;343:d5928. doi:10.1136/bmj.d5928

15. Higgins JP, Thompson SG, Deeks JJ, Altman DG. Measuring inconsistency in meta-analyses. BMJ. 2003;327(7414):557-560. doi:10.1136/bmj.327.7414.557

16. DerSimonian R, Laird N. Meta-analysis in clinical trials. Control Clin Trials. 1986;7(3):177-188.

17. Sterne JA, Egger M. Funnel plots for detecting bias in meta-analysis: guidelines on choice of axis. J Clin Epidemiol. 2001;54(10):10461055. doi:10.1016/s0895-4356(01)00377-8

18. McNeil JJ, Woods RL, Nelson MR, et al. Effect of aspirin on disability-free survival in the healthy elderly. $N$ Engl J Med. 2018;379(16):1499-1508. doi:10.1056/NEJMoa1800722

19. McNeil JJ, Nelson MR, Woods RL, et al. Effect of aspirin on allcause mortality in the healthy elderly. $N$ Engl J Med. 2018;379 (16):1519-1528. doi:10.1056/NEJMoa1803955
20. The Medical Research Council's General Practice Research Framework. Thrombosis prevention trial: randomised trial of lowintensity oral anticoagulation with warfarin and low-dose aspirin in the primary prevention of ischaemic heart disease in men at increased risk. Lancet. 1998;351(9098):233-241.

21. Belch J, MacCuish A, Campbell I, et al. The prevention of progression of arterial disease and diabetes (POPADAD) trial: factorial randomised placebo controlled trial of aspirin and antioxidants in patients with diabetes and asymptomatic peripheral arterial disease. BMJ. 2008;337:a1840. doi:10.1136/bmj.a1840

22. Fowkes FG, Price JF, Stewart MC, et al. Aspirin for prevention of cardiovascular events in a general population screened for a low ankle brachial index: a randomized controlled trial. JAMA. 2010;303(9):841-848. doi:10.1001/jama.2010.221

23. Saito Y, Okada S, Ogawa $\mathrm{H}$, et al. Low-dose aspirin for primary prevention of cardiovascular events in patients with type 2 diabetes mellitus: 10year follow-up of a randomized controlled trial. Circulation. 2017;135 (7):659-670. doi:10.1161/CIRCULATIONAHA.116.025760

24. Peto R, Gray R, Collins R, et al. Randomised trial of prophylactic daily aspirin in British male doctors. $\mathrm{Br}$ Med J (Clin Res Ed). 1988;296(6618):313-316. doi:10.1136/bmj.296.6618.313

25. Steering Committee of the Physicians' Health Study Research G. Final report on the aspirin component of the ongoing Physicians' Health Study. N Engl J Med. 1989;321(3):129-135. doi:10.1056/ NEJM198907203210301

26. ETDRS Investigators. Aspirin effects on mortality and morbidity in patients with diabetes mellitus. Early Treatment Diabetic Retinopathy Study report 14. JAMA. 1992;268(10):1292-1300. doi:10.1001/ jama.1992.03490100090033

27. Antithrombotic Trialists C, Baigent C, Blackwell L, et al. Aspirin in the primary and secondary prevention of vascular disease: collaborative meta-analysis of individual participant data from randomised trials. Lancet. 2009;373(9678):1849-1860. doi:10.1016/S0140-6736 (09)60503-1

28. Bartolucci AA, Tendera M, Howard G. Meta-analysis of multiple primary prevention trials of cardiovascular events using aspirin. Am J Cardiol. 2011;107(12):1796-1801. doi:10.1016/j.amjcard.2011.02.325

29. Raju N, Sobieraj-Teague M, Hirsh J, O’Donnell M, Eikelboom J. Effect of aspirin on mortality in the primary prevention of cardiovascular disease. Am J Med. 2011;124(7):621-629. doi:10.1016/j. amjmed.2011.01.018

30. Seshasai SR, Wijesuriya S, Sivakumaran R, et al. Effect of aspirin on vascular and nonvascular outcomes: meta-analysis of randomized controlled trials. Arch Intern Med. 2012;172(3):209-216. doi:10.1001/archinternmed.2011.628

31. Rothwell PM, Price JF, Fowkes FG, et al. Short-term effects of daily aspirin on cancer incidence, mortality, and non-vascular death: analysis of the time course of risks and benefits in 51 randomised controlled trials. Lancet. 2012;379(9826):1602-1612. doi:10.1016/ S0140-6736(11)61720-0
Therapeutics and Clinical Risk Management

\section{Publish your work in this journal}

Therapeutics and Clinical Risk Management is an international, peerreviewed journal of clinical therapeutics and risk management, focusing on concise rapid reporting of clinical studies in all therapeutic areas, outcomes, safety, and programs for the effective, safe, and sustained use of medicines. This journal is indexed on PubMed Central, CAS,
EMBase, Scopus and the Elsevier Bibliographic databases. The manuscript management system is completely online and includes a very quick and fair peer-review system, which is all easy to use. Visit http://www.dovepress.com/testimonials.php to read real quotes from published authors. 